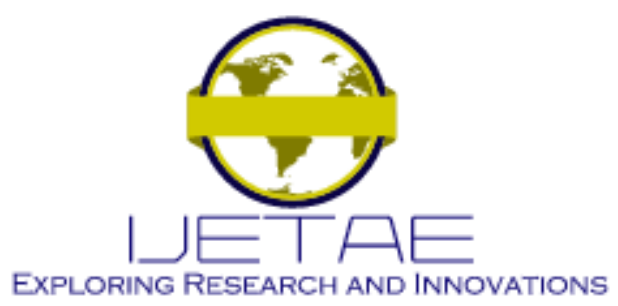

International Journal of Emerging Technology and Advanced Engineering

Website: www.ijetae.com (E-ISSN 2250-2459, Scopus Indexed, ISO 9001:2008 Certified Journal, Volume 11, Issue 11, November 2021)

Manuscript Received: 06 October 2021, Received in Revised form: 03 November 2021, Accepted:08 November 2021 DOI: 10.46338/ijetae1121_10

\title{
Effects of Pentagonal Pore Sizes in the Zinc Hydroxyapatite Parietal-Temporal Implant
}

\author{
Wan Nur Fatini Syahirah W. Dagang ${ }^{1}$, Nik Harisha Qistina Nik Hamdi ${ }^{2}$, Shahrul Hisyam Marwan ${ }^{3}$, \\ Jamaluddin Mahmud $^{4}$, Nor Fazli Adull Manan ${ }^{5}$, Muhammad Hanif Ramlee ${ }^{6}$, Abdul Halim Abdullah ${ }^{* 7}$ \\ ${ }^{1,2,4,5,{ }^{*} 7}$ School of Mechanical Engineering, College of Engineering, Universiti Teknologi MARA (UiTM), \\ 40450 Shah Alam, Selangor, Malaysia. \\ ${ }^{3}$ School of Mechanical Engineering, College of Engineering, Universiti Teknologi MARA (UiTM) \\ Terengganu Branch, Bukit Besi Campus, 23200 Dungun, Terengganu, Malaysia. \\ ${ }^{6}$ Medical Devices \& Technology Centre (MEDiTEC), Institute of Human Centered Engineering (iHumEn), Universiti \\ Teknologi Malaysia, 81310 UTM Johor Bahru, Johor, Malaysia. \\ (*Corresponding Author's Email: halim471@uitm.edu.my)
}

\begin{abstract}
To reconstruct the fractured skull, affected patients are advised to undergo cranioplasty, which is a surgical procedure to repair the cranial defect by implanting materials such as autologous bone grafts or synthetic alloplastic materials. The use of synthetic alloplastic materials such as hydroxyapatite (HA) has been widely accepted due to their biocompatibility and suitability for larger cranial defects. The zinc hydroxyapatite ( $\mathrm{ZnHA})$ material is favourable as HA mimics $60 \%$ of the actual human bone, whereas zinc helps to improve its biomechanical properties. The purpose of this study is to construct the $\mathrm{ZnHA}$ cranial implant with different pore sizes of 600,900 , and $1200 \mu \mathrm{m}$ in pentagonal shapes and to study its mechanical performance. At the end of the research, it was found that the implant with a pore size of $900 \mu \mathrm{m}$ is the most appropriate implant to be utilized without affecting its mechanical performance. Aspects such as the deformation and von Mises stress are discussed to assist on the development of the ZnHA cranial implant.
\end{abstract}

Keywords - Biomechanical analysis, cranial implant, finite element analysis, pore size, zinc hydroxyapatite.

\section{INTRODUCTION}

The human skull is composed of bones which support many organs, most importantly as a protective cavity for the brain. It is divided into two regions which is the neurocranium and viscerocranium. The neurocranium is considered the superior part of the skull as it maintains the shape of the head and protects the brain, whereas the viscerocranium gives facial support. The neurocranium comprises eight bones which include the frontal, sphenoid, temporal, parietal, occipital, and ethmoid bones.
The head is prone to injury from occurrences such as being hit with an object, falling, and vehicle crashes. Generally, the injuries are grouped into three categories scalp damage, brain injury, and skull fracture. The skull fracture occurs when the mechanical impact or loading exceeds the skull's tolerance limit [1], [2]. Based on the study done by Sahoo et al. [2], it was found that the parietal-temporal region is more vulnerable to injury, followed by the occipital and frontal regions.

Patients with skull fractures are advised to undergo cranioplasty, which is a neurosurgical procedure to repair cranial defects by restoring the contour of the skull. Cranioplasty is necessary as it maintains the appearance of the head and acts as a physical barrier for the cerebral structures. The procedure is done by filling the defect with autologous bone grafts, which can be obtained from the patient's rib, skull, or pelvis. However, there would be some cases where using synthetic alloplastic materials would be preferable. Cranioplasty has been a significant medical procedure ever since 1523, where Fallopius, an anatomist, successfully restored the fractured dura of the meninges region with a gold plate [3]. Similar to other surgical procedures, cranioplasty comes with the risk of complications and failures, which can affect the patient's condition post-operation. As reported by Sahoo et al. [4], the material used for the reconstruction has an influence towards the success of the procedure. Furthermore, Parthasarathay [5] also states that the success of the procedure and longevity of the implants depends on aspects such as the design of the implant, material characteristics, as well as the surgeon's skills. 


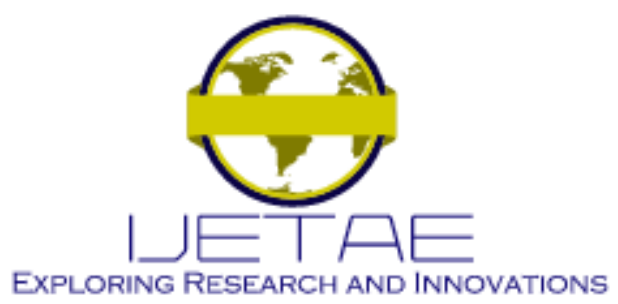

International Journal of Emerging Technology and Advanced Engineering

Website: www.ijetae.com (E-ISSN 2250-2459, Scopus Indexed, ISO 9001:2008 Certified Journal, Volume 11, Issue 11, November 2021)

Based on past cranioplasty procedures, the materials used are divided into four categories which include xenografts, allografts, autologous bone grafts, and synthetic materials. Xenografts are obtained from animal tissues, where allografts are derived from suitable donors. Due to that, autologous bone grafts which come from the same patient are preferred as this does not introduce foreign materials into the body [6]. Autologous bone grafts are also more biologically compatible, consumes less cost, and are easier in terms of contour restoration [7], [8]. However, there are some disadvantages in utilizing autologous bone grafts. Based on a study done by Bach Nguyen et al. [7], the use of preserved bone flaps has high risk of bone resorption with a percentage of $22 \%$ and $50 \%$ among adults and paediatric patients, respectively. In the event of bone resorption, this would result in short margins and poor fitting of the cranial implant post-operation. Hence, synthetic materials are a good alternative when performing cranioplasty.

The synthetic materials commonly used for cranioplasty include titanium (Ti6Al4V), polymethylmethacrylate (PMMA), hydroxyapatite (HA), and polyetheretherketone (PEEK). In most cranioplasty procedures, titanium is a material of choice for its biocompatibility, strength to weight ratio and osteoconductive property which is the formation of new bone within the implant [5]. This is supported by Aatman M. Shah et al. [6] which states that the titanium implant had the lowest rate of infection at only $2.6 \%$. However, it also has a disadvantage which is titanium implant can cause stress shielding at the boneimplant contact because it has a higher modulus of elasticity compared to the bone [9]. Furthermore, the metallic implant may cause corrosion as well as cytotoxic reactions inside the host body due to the release of metal ions [10]. PEEK is also commonly used, which is a semicrystalline thermoplastic polymer with excellent thermal, chemical, and mechanical properties. As compared to metals, PEEK is favourable as they do not conduct temperature that might induce negative consequences to the brain [6]. PMMA has similar properties as PEEK material. The advantages of PMMA material are easy to handle during the surgical procedure and low post-surgical inflammation [11]. Still, it is not without its weakness. PMMA implant has poor adhesion to the soft tissues that surround them [10]. Additionally, PMMA has a smooth texture that inhibits tissue regeneration [12]. HA is suitable for reconstructing cranial defects as it constitutes $60 \%$ of the actual human bone.
It has advantageous properties to support the success of the surgical procedure such as allowing bone integration, new bone deposition at the implantation site, as well as permitting expansion of the skull which is beneficial for paediatric patients [6], [8], [13]. By allowing the formation of new bone within the prosthesis, the implant can act as a matrix while the bone as reinforcement which further strengthens the structure. However, the use is limited due to its brittleness and low tensile strength. Hence, there have been many past studies on incorporating ions such as magnesium $(\mathrm{Mg})$, iron $(\mathrm{Fe})$ and zinc $(\mathrm{Zn})$ with the HA to improve its mechanical properties [14], [15]. The use of Fe as the substituent is limited due to its higher elastic modulus and slower corrosion rate. Meanwhile, $\mathrm{Mg}$ produces more hydrogen gas which contributes to the rapid degradation rate. To overcome this issue, the $\mathrm{Zn}$ was believed to be the most suitable ion to be used with the HA because it has an optimum degradation rate, and it is important in human nutrition [16]. Moreover, past studies also reported that zinc-hydroxyapatite (ZnHA) enhance bone ingrowth and healing the damage [17]. Therefore, zinc-hydroxyapatite ( $\mathrm{ZnHA}$ ) material will be used as the subject in this study.

Besides choosing the right material for the cranial implant, it is also necessary to justify the right parameters such as pore size, percentage of porosity, and pore shape as this highly affects bone regeneration within the prosthesis. Porous surface is important as it enhances tissue proliferation and mechanical interlocking between the implant and the surrounding tissues which result in longterm fixation [18], [19]. Higher porosity is favourable for more bone ingrowth, but it causes a reduction in mechanical properties; hence there must be an upper limit for pore size as well as porosity [18], [20]. However, the exact suitable pore size remains unclear. Most researchers believe that the appropriate pore size to be incorporated is about $150-600 \mu \mathrm{m}$, but a pore size more than $300 \mu \mathrm{m}$ is recommended to enhance better bone ingrowth [18], [20]. A study done by M. Lopez-Heredia et al. [21] shows that the strength and young's modulus is influenced by the porosity. In addition, adjusting the pore size and porosity of the implant can improve its density, strength, and mechanical compatibility to prevent osteogenesis deformity [22]. The pore shape of the implant also plays an important role, whether it is circular, triangular, hexagonal, or others. As stated by Diez-Escudero et al. [19], the geometry is important as the sharp-angled pores are actually beneficial for tissue differentiation. 


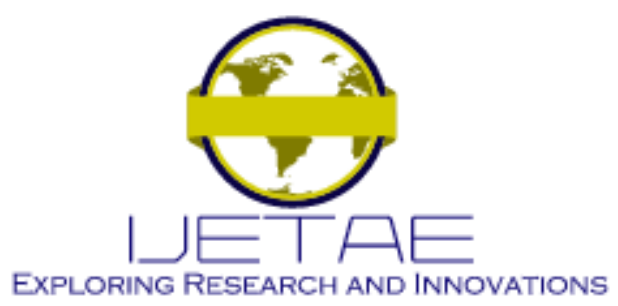

International Journal of Emerging Technology and Advanced Engineering

Website: www.ijetae.com (E-ISSN 2250-2459, Scopus Indexed, ISO 9001:2008 Certified Journal, Volume 11, Issue 11, November 2021)

Therefore, this study aims to reconstruct zinc-reinforced hydroxyapatite (ZnHA) cranial implant for the parietaltemporal region and to assess its biomechanical behaviour based on different pore sizes of 600,900 , and $1200 \mu \mathrm{m}$ with pentagonal shapes. The variable of the pore size must be studied further to ensure optimum bone regeneration without sacrificing its mechanical properties. Furthermore, it is required to seek the balance between the parameters of the implant such as pore size, porosity, and pore shape with its strength. To study its mechanical behaviour, the model will be put under $50 \mathrm{~N}$ load which is the weight of the human head at resting position, as well as $2000 \mathrm{~Pa}$ intracranial pressure. The results of von Mises stress and deformation will be discussed at the end of the study.

\section{Methodology}

\section{A. Development of Human Skull with Parietal-Temporal Implant}

The 3D model of the human skull was obtained by using the Sense 3D Scanner. Firstly, the human skull model as shown in Figure 1 was placed in a well-lit area to ensure the features of the skull model could be captured entirely. After setting up the 3D Systems Sense (3D Systems, Rock Hill, South Carolina) software, the scanner was moved around the skull model. During this step, the scanner was moved around slowly to ensure the entire shape and appearance were being transferred to the system.

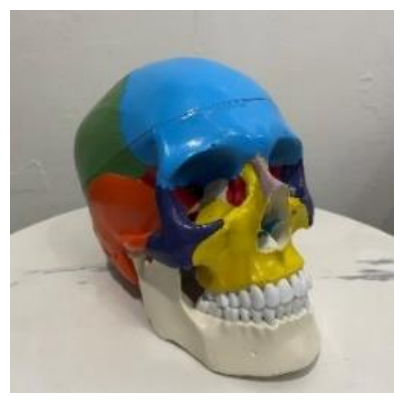

Figure 1: Human skull model

The 3D model after the scanning process has been completed. It was found that there were some unfilled holes on the model due to the inaccuracy of the scanning process. Therefore, the "solidify" feature on the software was used to fix the defect. The complete 3D model was then saved in OBJ format which is a standard 3D image viewing format as shown in Figure 2.

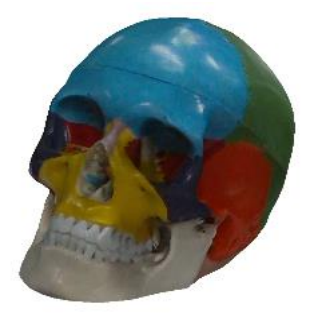

Figure 2: Complete 3D model human skull in OBJ format after scanning process

Lastly, the file was converted to STL format as illustrated in Figure 3 for further editing. The reason for using the STL file over the OBJ file is that the STL file is generally recognized and widely used with almost all software. This is because of its simplicity and versatility, making it easier to process.

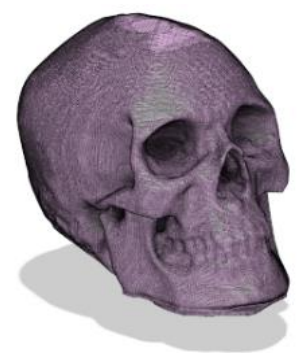

Figure 3: 3D model of human skull model in STL format

The human skull was modified to remove the parietaltemporal region, as shown in Figure 4. The procedure of the reconstruction model was conducted based on Dagang et al. [23] using 3-Matic 13.0 (Materialize NV, Leuven, Belgium). Then, the parietal-temporal region of the skull was extracted as illustrated in Figure 5 (a). The model was modified by inserting the pentagonal-shaped pores. Different pore sizes of 600,900 , and $1200 \mu \mathrm{m}$ with pentagonal shapes can be incorporated onto the cranial implant.

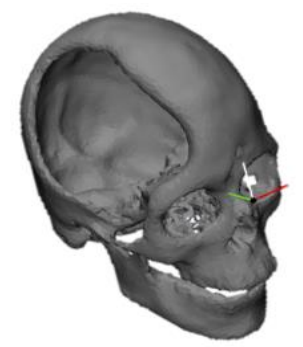

Figure 4: The 3D human skull model that parietal- temporal region has been removed 


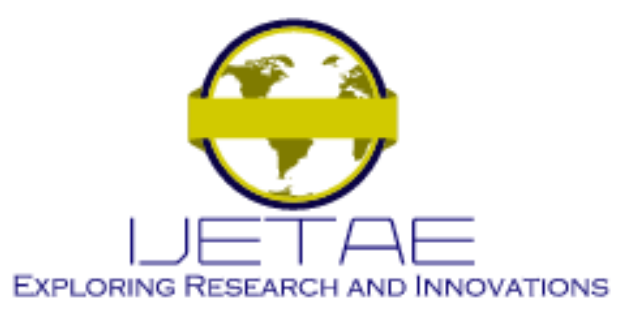

International Journal of Emerging Technology and Advanced Engineering

Website: www.ijetae.com (E-ISSN 2250-2459, Scopus Indexed, ISO 9001:2008 Certified Journal, Volume 11, Issue 11, November 2021)

Then, the point-based pattern tool was used to assign the prosthesis, prism, and grouped patterns as the entity, pattern entity, and parts, respectively. The pattern entity was then created along the z-direction with a depth of 7 $\mathrm{mm}$. Lastly, the Boolean subtraction was performed to extract the prisms to form a porous cranial implant as illustrated in Figure 5 (b). These processes are then repeated to design a prosthesis with 900 and $1200 \mu \mathrm{m}$ pore size.

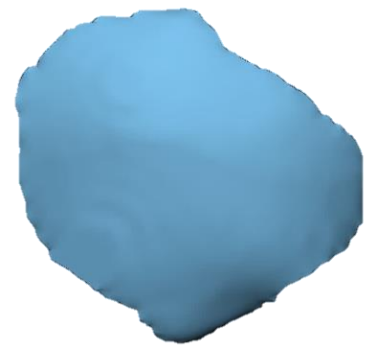

(a)

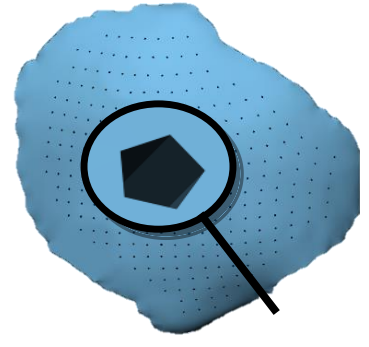

(b)
Figure 5: (a) Extracted parietal-temporal region (b) Implant with pentagonal-shaped pores

\section{B. Biomechanical Analysis}

To assess the biomechanical performance of the ZnHA cranial implant, there are several steps that should be done on Abaqus 6.14 (Dassault Systèmes, Vélizy-Villacoublay, France) software. Firstly, the workbench module is changed to 'property' before importing the cranial implant and skull into the software. After the two parts are imported, they have been assigned as a homogenous solid with uniform composition. The cranial implant and defected skull are assigned to their materials which are ZnHA and bone, respectively. The young's modulus and Poisson's ratio of the materials are as shown in TABLE I.

TABLE I

Material Properties of Bone ANd ZnHa

\begin{tabular}{|c|c|c|}
\hline Material & Young's Modulus (GPa) & Poisson's Ratio \\
\hline Bone & 15 & 0.3 \\
\hline ZnHA & 6 & 0.3 \\
\hline
\end{tabular}

The process is then followed by meshing the parts individually. The element shape was set to be tetrahedral with a global size of 1.6 for the implant, whereas the skull was set to a global size of 4 . The mesh parts are as illustrated in Figure 6 (a) and (b).

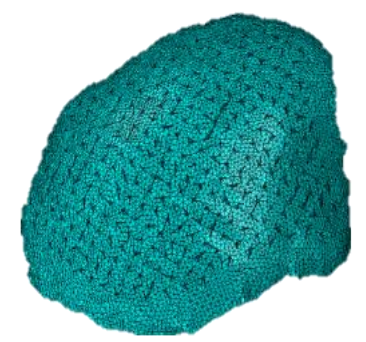

(a)

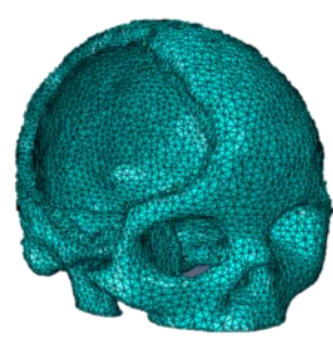

(b)
Figure 6: Meshing with tetrahedral elements (a) Cranial implant after meshing (b) Defected skull after meshing

After the meshing is completed, the cranial implant and defected skull are assembled to form a reconstructed parietal-temporal skull as shown in Figure 7. The process is done by creating a constraint between two points. One point is selected on the implant and another is selected on the skull to specify its coincident point.

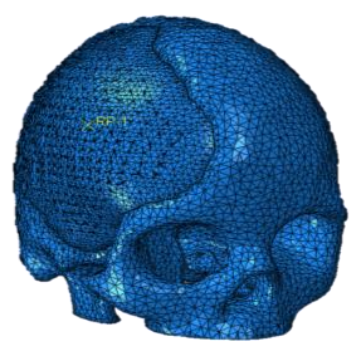

Figure 7: Reconstructed cranial defect

Three different surfaces were defined to assess the performance of the model. These surfaces include the skull interface and implant interface, which indicates the interaction surface between the two parts. After selecting these areas, the master and slave surfaces were then assigned to the skull interface and implant interface, respectively, to form the interaction region as shown in Figure 8 (a). Besides that, the load surface in Figure 8 (b) and intracranial pressure surface in Figure 8 (c) was also defined to denote the area of where the external loads will be placed. 


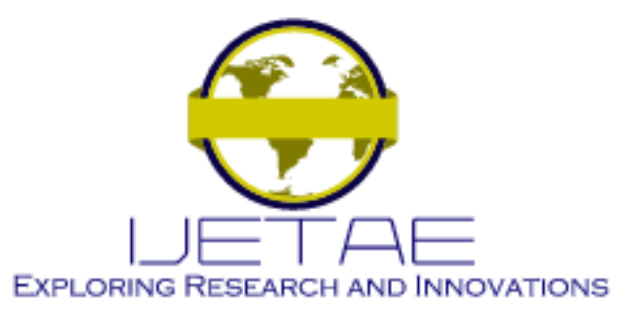

International Journal of Emerging Technology and Advanced Engineering

Website: www.ijetae.com (E-ISSN 2250-2459, Scopus Indexed, ISO 9001:2008 Certified Journal, Volume 11, Issue 11, November 2021)

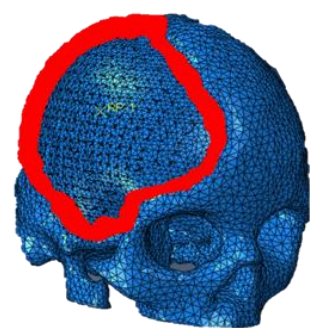

(a)

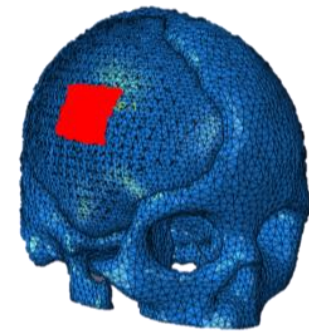

(b)

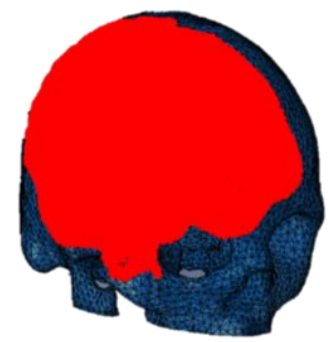

(c)

Figure 8: Steps in selecting surfaces on the parts (a) Interaction surface on the reconstructed cranial defect (b) Load surface (c) Intracranial pressure surface

To assess the performance of the implant thoroughly, external load or pressure are taken into consideration for the analysis as shown in TABLE II. The load was set to 50 $\mathrm{N}$ as shown in Figure 9 (a), which corresponds to the weight of the human head while resting on a pillow. The load value is converted into pressure whereby the area of the surface selected earlier was considered. Based on the intracranial pressure surface selected, it gives an area of $8.118 \times 10-4 \mathrm{~m} 2$. Hence, the value of load pressure is $61593 \mathrm{~Pa}$. Furthermore, the intracranial pressure was set to $15 \mathrm{mmHg}(2000 \mathrm{~Pa})$ which is the maximum pressure exerted on the cranial implant at rest. The pressure setting is illustrated in Figure 9 (b). Lastly, fixed support was set at the bottom part of the skull as shown in Figure 9 (c).

TABLE II

VALUE OF EXTERNAL LOAD ON CRANIAL IMPLANT

\begin{tabular}{|c|c|}
\hline Surface & Pressure (Pa) \\
\hline Load surface & 61593 \\
\hline Intracranial pressure surface & 2000 \\
\hline
\end{tabular}

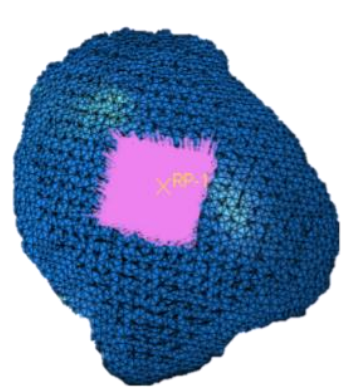

(a)

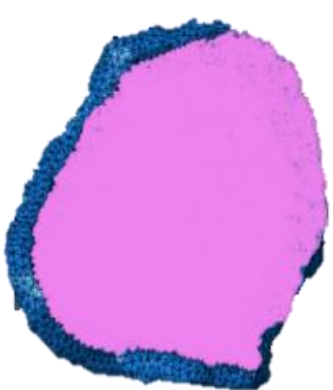

(b)

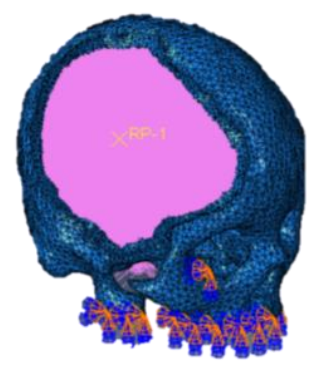

(c)

Figure 9: Define load and boundary condition (a) $50 \mathrm{~N}$ load on the implant (b) Intracranial pressure exerted on the implant (c) Fixed support on the skull

The previous steps are repeated for the three reconstructed skulls of different sizes which are 300, 450, and $600 \mu \mathrm{m}$ pentagonal radius. After defining all the necessary elements, the analysis is performed by creating a job model as shown in Figure 10. The results were obtained once the analysis had been completed.

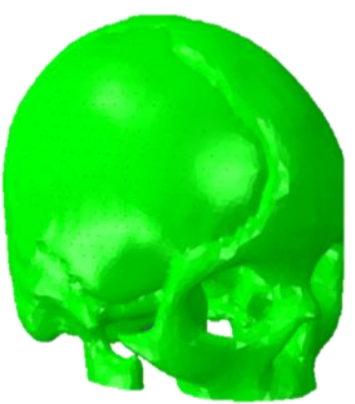

Figure 10: Job completed 


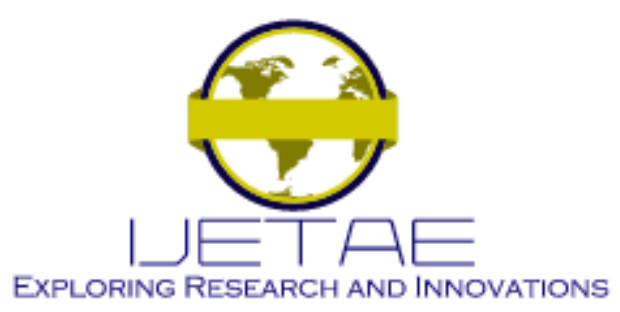

International Journal of Emerging Technology and Advanced Engineering

Website: www.ijetae.com (E-ISSN 2250-2459, Scopus Indexed, ISO 9001:2008 Certified Journal, Volume 11, Issue 11, November 2021)

\section{RESULTS}

When assessing the biomechanical performance of the model, two aspects are being monitored which are the stress distribution and deformation. Figure 11 and 12 summarize the stress distribution of the cranial implant and skull when subjected to $50 \mathrm{~N}$ load as well as $2000 \mathrm{~Pa}$ intracranial pressure. It was found that the stress distribution pattern on the implants with different pore structures are similar. However, it is clearly shown that the stress distribution on the right and bottom regions of the implant is much higher than the left and top regions for all three pore sizes. As described in TABLE III, the implant with pore size of $600 \mu \mathrm{m}$ gives off the highest maximum stress with $8.02 \mathrm{MPa}$, followed by $1200 \mu \mathrm{m}$, and lastly 900 $\mu \mathrm{m}$ with the lowest maximum stress of $2.09 \mathrm{MPa}$. Furthermore, the maximum stress exerted onto the implant is varies between the three pore sizes. However, the trend differs with the stress exerted onto the skull. The maximum stress does not exhibit such a significance difference between the three models. The lowest maximum stress occurs on the skull with pore size of $600 \mu \mathrm{m}$, which is $0.834 \mathrm{MPa}$, while the value of maximum stress for pore size 900 and $1200 \mu \mathrm{m}$ were $0.836 \mathrm{MPa}$ and $0.840 \mathrm{MPa}$ respectively.
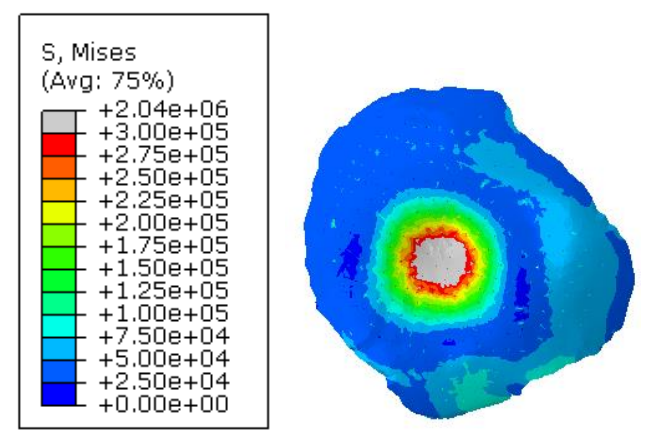

(a)

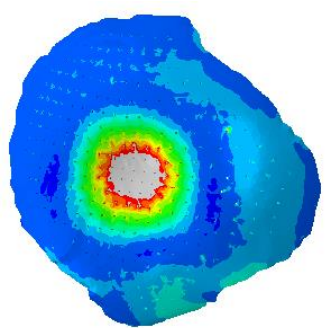

(b)

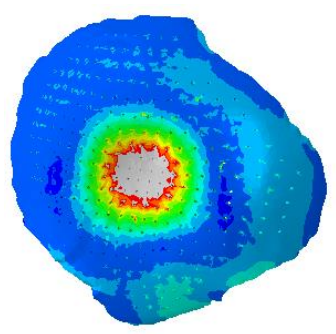

(c)
Figure 11: Stress distribution of the implant (a) $600 \mu \mathrm{m}$ (b) $900 \mu \mathrm{m}$ (c) $1200 \mu \mathrm{m}$
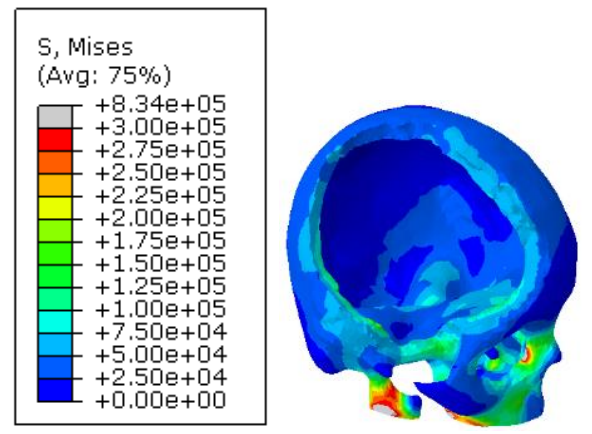

(a)

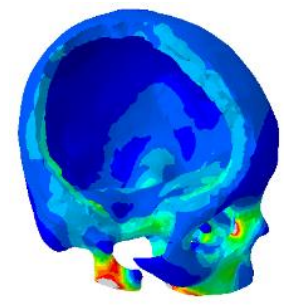

(b)

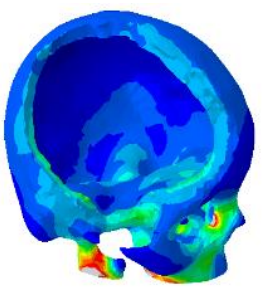

(c)
Figure 12: Stress distribution of the skull (a) $600 \mu \mathrm{m}$ (b) $900 \mu \mathrm{m}$ (c) $1200 \mu \mathrm{m}$

TABLE III

MAXIMUM STRESS EXERTED ON THE ZNHA CRANIAL IMPLANT AND SKUL

\begin{tabular}{|c|c|c|}
\hline $\begin{array}{c}\text { Pore Size } \\
(\boldsymbol{\mu m})\end{array}$ & $\begin{array}{c}\text { Maximum stress } \\
\text { on the implant } \\
(\mathbf{M P a})\end{array}$ & $\begin{array}{c}\text { Maximum stress } \\
\text { on the skull } \\
(\mathbf{M P a})\end{array}$ \\
\hline 600 & 8.02 & 0.834 \\
\hline 900 & 2.09 & 0.836 \\
\hline 1200 & 5.69 & 0.840 \\
\hline
\end{tabular}

Figure 13 and 14 shows the deformation distribution of the cranial implant and skull, respectively. Similarly, to assess its deformation, the model is also put under $50 \mathrm{~N}$ load and $2000 \mathrm{~Pa}$ intracranial pressure. In terms of its deformation, the three pore sizes do not display a huge difference between one another. As for the cranial implant, the deformation is highest in the region where the load is applied. As tabulated in TABLE IV, the pore size of 1200 $\mu \mathrm{m}$ shows the highest maximum deformation of $7.64 \mathrm{~mm}$. In contrast, the implant with a pore size of $600 \mu \mathrm{m}$ shows the lowest maximum deformation of $7.44 \mathrm{~mm}$. The skull with a pore size of $1200 \mu \mathrm{m}$ shows the highest maximum deformation of $4.89 \mathrm{~mm}$, followed by the pore size of 900 $\mu \mathrm{m}$ with $4.87 \mathrm{~mm}$, and lastly pore size of $600 \mu \mathrm{m}$ with $4.86 \mathrm{~mm}$. 


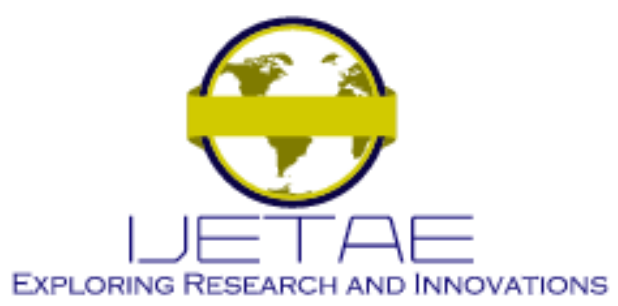

International Journal of Emerging Technology and Advanced Engineering

Website: www.ijetae.com (E-ISSN 2250-2459, Scopus Indexed, ISO 9001:2008 Certified Journal, Volume 11, Issue 11, November 2021)

For its distribution, the trend is similar for both implant and skull for all three pore sizes. The distribution for the implant depicts that the deformation increases from the bottom up of the model. Whereas for the skull, the maximum deformation generally occurs at the top of the skull.
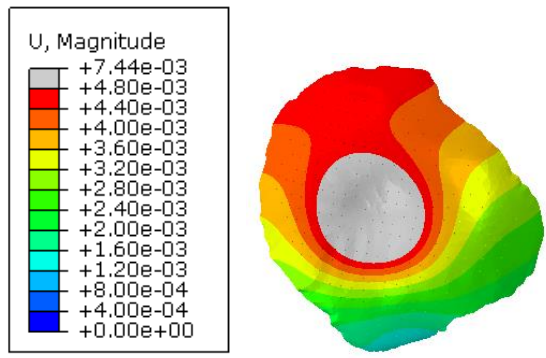

(a)

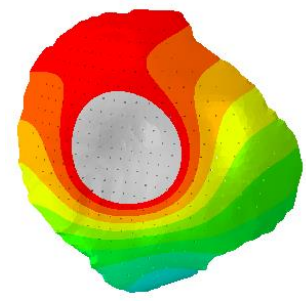

(b)

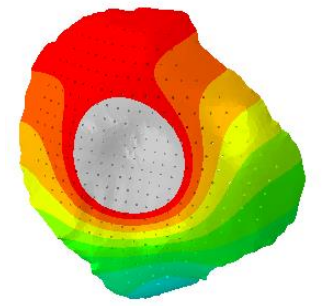

(c)
Figure 13: Deformation of the implant (a) $600 \mu \mathrm{m}$ (b) $900 \mu \mathrm{m}$ (c) 1200 $\mu \mathrm{m}$
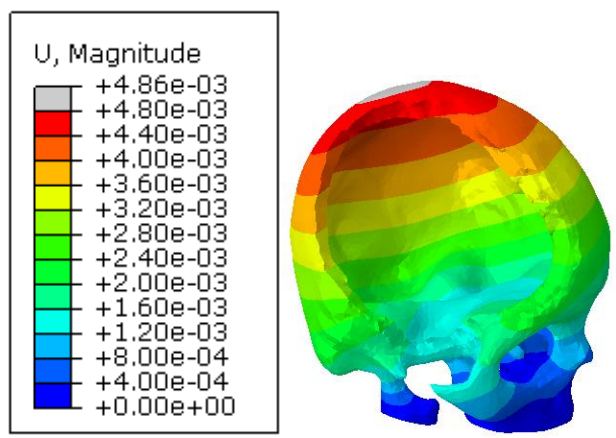

(a)

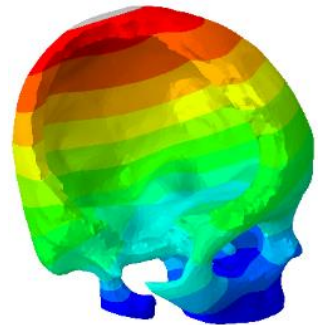

(b)

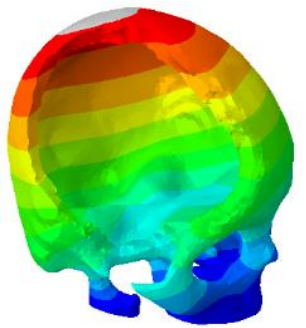

(c)
Figure 14: Deformation of the skull (a) $600 \mu \mathrm{m}$ (b) $900 \mu \mathrm{m}$ (c) 1200 $\mu \mathrm{m}$

TABLE IV

MAXIMUM DEFORMATION ON THE ZNHA CRANIAL IMPLANT AND SKULL

\begin{tabular}{|c|c|c|}
\hline $\begin{array}{c}\text { Pore Size } \\
(\boldsymbol{\mu m})\end{array}$ & $\begin{array}{c}\text { Maximum } \\
\text { deformation on the } \\
\text { implant }(\mathbf{m m})\end{array}$ & $\begin{array}{c}\text { Maximum } \\
\text { deformation on } \\
\text { the skull (mm) }\end{array}$ \\
\hline 600 & 7.44 & 4.86 \\
\hline 900 & 7.52 & 4.87 \\
\hline 1200 & 7.64 & 4.89 \\
\hline
\end{tabular}

\section{DISCUSSION}

In this study, the skull with the parietal-temporal defect was reconstructed by designing zinc-reinforced hydroxyapatite (ZnHA) cranial implant. In constructing the prosthesis, aspects such as material, pore shape, and pore size are important in determining its rate of bone ingrowth as well as its mechanical properties. Based on past researchers, porous implants are necessary to facilitate tissue proliferation. However, as the size of pores increase, it affects the mechanical strength by reducing its resistance to impact loading. Hence, three cranial implants were constructed with pore sizes of 600,900 , and $1200 \mu \mathrm{m}$ to assess their biomechanical performance. The models were subjected to $50 \mathrm{~N}$ which is the weight of the human head at resting position, and $2000 \mathrm{~Pa}$ intracranial pressure that is exerted by fluids such as cerebrospinal fluid and brain tissue. 


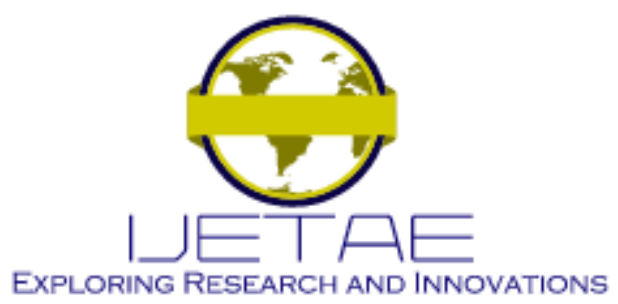

International Journal of Emerging Technology and Advanced Engineering

Website: www.ijetae.com (E-ISSN 2250-2459, Scopus Indexed, ISO 9001:2008 Certified Journal, Volume 11, Issue 11, November 2021)

After analyzing the results obtained, the trend shows that the maximum stress exerted on the implant drops from 600 to $900 \mu \mathrm{m}$ but increases for the pore size of $1200 \mu \mathrm{m}$. This shows that the mechanical properties have been affected by large porosity. Besides that, as illustrated in Figure 15, the deformation increases as the pore size increases. Even so, the deformation of the three implant models does not show a significant difference with only a variable of about 0.08 $\mathrm{mm}$. The maximum deformation of the pore size of 1200 $\mu \mathrm{m}$ increases greatly resulted by the sharp increase of maximum stress exerted. Similar to the study done by Haen et al. [24] on the temporal region, the maximum stress and deformation of the cranial implant are highest at the location where the load is applied.

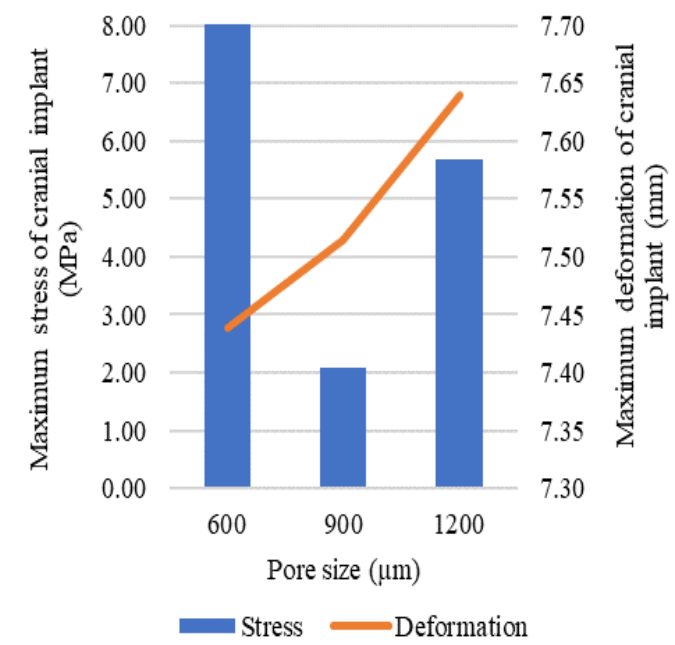

Figure 15: Graph of maximum stress and deformation of the implant against pore sizes

Figure 16 shows the maximum stress and deformation experienced by the skull with implants of different pore sizes. The results show a specific trend whereby the maximum stress and deformation increase as the pore size increases. Furthermore, the maximum stress exerted on the skull is located near the mandible area, similar for all three models. Compared to the results done with a full skull by Holberg et al. [25], it was found that the highest stress generally occurs at the cranial base which is located at the bottom of the skull. The said region is prone to higher stress as it has increased vulnerability due to the presence of neural and vascular structures.
In the same study, based on the analysis done on the human skull, it is concluded that the different regions of the skull result in different values of von Mises stress. Naturally, this is caused by the variations of bone thickness, quality, and bone elasticity. Hence, the results in this study do not depict a specific trend as these variations were not taken into consideration.

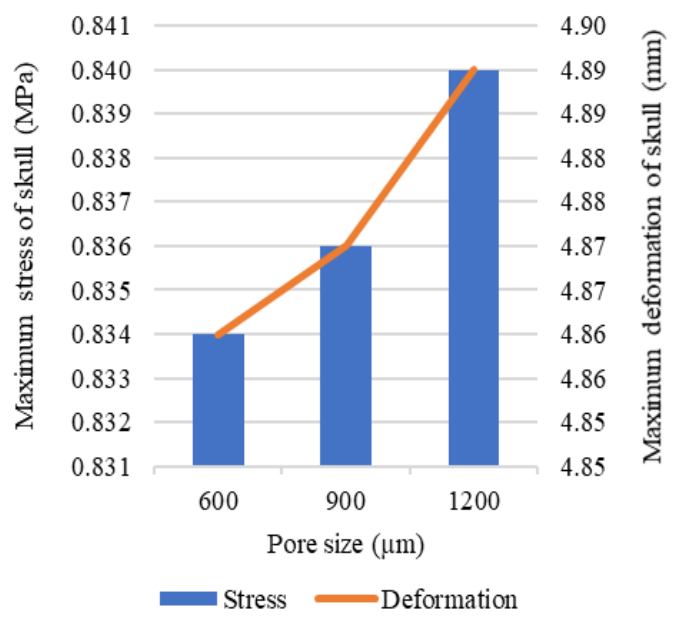

Figure 16: Graph of maximum stress and deformation of the skull against pore sizes

In determining the mechanical performance of the cranial implant, the safety factor was calculated and analyzed as tabulated in TABLE V. To predict the failure of a particular model, the maximum stress applied should not exceed the material's ultimate strength which is the maximum stress before a fracture occurs. As obtained by Pinc et al. [26], ZnHA has an ultimate strength of 168.90 MPa. The results show that all three models are reliable as they would not fail under the loading conditions. However, it exhibits that pore size of $900 \mu \mathrm{m}$ has the highest value of safety factor, followed by $600 \mu \mathrm{m}$ and $1200 \mu \mathrm{m}$. Therefore, it can be said that the cranial implant with pore size $900 \mu \mathrm{m}$ is the most appropriate design to be implemented. In addition, the prosthesis also does not cause high stress or deformation on the skull.

As mentioned in previous studies, porous implants are necessary to enhance tissue proliferation which results in mechanical interlocking between the prosthesis and the skull. The pore shape and size have a significant effect on bone ingrowth. 


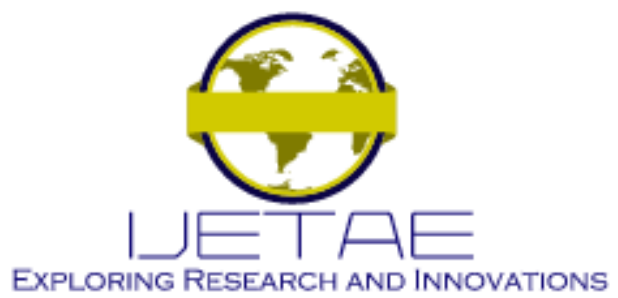

International Journal of Emerging Technology and Advanced Engineering

Website: www.ijetae.com (E-ISSN 2250-2459, Scopus Indexed, ISO 9001:2008 Certified Journal, Volume 11, Issue 11, November 2021)

Based on Zheng et al. [18], pore sizes of 400 and 700 $\mu \mathrm{m}$ shows enough evidence for bone ingrowth. But generally, pore sizes of more than $300 \mu \mathrm{m}$ are recommended as it enhances bone formation. Therefore, the cranial implant with $900 \mu \mathrm{m}$ is suitable to be utilized as it boosts bone regeneration without sacrificing its mechanical properties.

TABLE V

SAFETY FACTOR OBTAINED FOR 600, 900, AND $1200 \mu$ M PORE SIZES

\begin{tabular}{|c|c|c|c|}
\hline $\begin{array}{c}\text { Pore Size } \\
(\boldsymbol{\mu m})\end{array}$ & $\begin{array}{c}\text { Ultimate } \\
\text { Strength } \\
(\mathbf{M P a})\end{array}$ & $\begin{array}{c}\text { Maximum } \\
\text { Stress } \\
(\mathbf{M P a})\end{array}$ & $\begin{array}{c}\text { Safety } \\
\text { Factor }\end{array}$ \\
\hline 600 & 168.90 & 8.02 & 21.06 \\
\hline 900 & 168.90 & 2.09 & 80.81 \\
\hline 1200 & 168.90 & 5.69 & 29.68 \\
\hline
\end{tabular}

\section{CONCLUSION}

The skull with the parietal-temporal defect was successfully restored by constructing a ZnHA cranial implant. The CT scan of the defected skull was transferred into a 3D model to construct a patient-specific prosthesis. $\mathrm{ZnHA}$ is a suitable material as a cranial implant due to its biocompatibility. Hydroxyapatite constitutes $80 \%$ of the actual human bone and it allows tissue proliferation and bone regeneration, whereas zinc is introduced to further improve the mechanical performance of the material. Besides choosing the right material, its pore shape and size also plays an important role to enhance bone regeneration and inducing mechanical interlocking. These aspects should be analyzed further to promote tissue proliferation without affecting its strength. Hence, it is necessary to seek the balance between the rate of bone regeneration and its mechanical properties. Although the objective of this study is achieved, the scope is only limited to stationary loading where the human is at a resting position. Aspects such as variations of bone thickness, quality, and bone elasticity were also not taken into consideration which affects the stress distribution of the human skull. To further improve the results of this study, the said aspects should be studied as well. In addition, the skull model should also be tested with subject to dynamic loading to justify its design conformance.

\section{Acknowledgement}

This study was funded by the University Teknologi MARA in Malaysia and the Malaysian Ministry of Higher Education through the FRGS research grant No. 600IRMI/FRGS 5/3 (162/2019). We want to thank our partners from UiTM Cawangan Pulau Pinang for the technical support and AA 3D Technology Sdn. Bhd. for sharing their expertise on 3D scanning.

\section{REFERENCES}

[1] D. Garcia-Gonzalez et al., "On the mechanical behaviour of PEEK and HA cranial implants under impact loading," J. Mech. Behav. Biomed. Mater., vol. 69, no. January, pp. 342-354, 2017, doi: 10.1016/j.jmbbm.2017.01.012.

[2] D. Sahoo, C. Deck, N. Yoganandan, and R. Willinger, "Development of skull fracture criterion based on real-world head trauma simulations using finite element head model," J. Mech. Behav. Biomed. Mater., vol. 57, pp. 24-41, 2016, doi: 10.1016/j.jmbbm.2015.11.014.

[3] A. Alkhaibary, A. Alharbi, N. Alnefaie, A. Aloraidi, and S. Khairy, "Cranioplasty: A Comprehensive Review of the History, Materials, Surgical Aspects, and Complications," World Neurosurg., vol. 139, pp. 445-452, 2020, doi: 10.1016/j.wneu.2020.04.211.

[4] N. K. Sahoo, K. Tomar, A. Thakral, and S. Kumar, "Failures in cranioplasty - A clinical audit \& review," J. Oral Biol. Craniofacial Res., vol. 11, no. 1, pp. 66-70, 2020, doi: 10.1016/j.jobcr.2020.11.013.

[5] J. Parthasarathy, "3D modeling, custom implants and its future perspectives in craniofacial surgery," Ann. Maxillofac. Surg., vol. 4, no. 1, pp. 9-18, 2014, doi: 10.4103/2231-0746.133065.

[6] A. M. Shah, H. Jung, and S. Skirboll, "Materials used in cranioplasty: A history and analysis," Neurosurg. Focus, vol. 36, no. 4, pp. 1-7, 2014, doi: 10.3171/2014.2.FOCUS13561.

[7] A. Santhosh Mathew and D. Goswami, "Cranioplasty Using Customized 3D-Printed Titanium Implants: An International Collaboration Effort to Improve Neurosurgical Care," Econ. Polit. Wkly., vol. 51, no. 17, pp. 110-118, 2016, doi: $10.1177 / 8756870517703395$.

[8] L. Kihlström Burenstam Linder, U. Birgersson, K. Lundgren, C. Illies, and T. Engstrand, "Patient-Specific Titanium-Reinforced Calcium Phosphate Implant for the Repair and Healing of Complex Cranial Defects," World Neurosurg., vol. 122, pp. e399-e407, 2019, doi: 10.1016/j.wneu.2018.10.061.

[9] K. Moiduddin, S. Darwish, A. Al-Ahmari, S. ElWatidy, A. Mohammad, and W. Ameen, "Structural and mechanical characterization of custom design cranial implant created using additive manufacturing," Electron. J. Biotechnol., vol. 29, pp. 22-31, 2017, doi: 10.1016/j.ejbt.2017.06.005.

[10] S. Jindal, F. Manzoor, N. Haslam, and E. Mancuso, “3D printed composite materials for craniofacial implants: current concepts, challenges and future directions," Int. J. Adv. Manuf. Technol., vol 112, no. 3-4, pp. 635-653, 2021, doi: 10.1007/s00170-020-06397-1. 


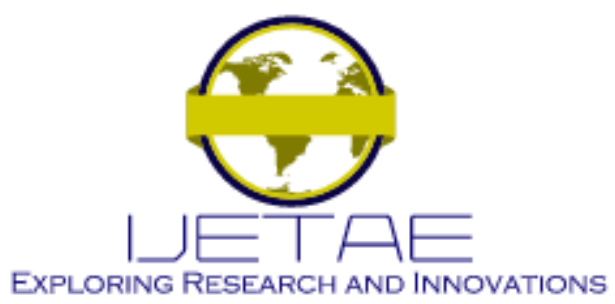

International Journal of Emerging Technology and Advanced Engineering

Website: www.ijetae.com (E-ISSN 2250-2459, Scopus Indexed, ISO 9001:2008 Certified Journal, Volume 11, Issue 11, November 2021)

[11] D. J. Bonda, S. MAnjila, W. R. Selman, and D. David, "The Recent Revolution in the Design and Manufacture of Cranial Implants: Modern Advancements and Future Directions," vol. 77, no. 5, pp. 814-824, 2016, doi: 10.1227/NEU.0000000000000899.The.

[12] M. C. Goiato, R. B. Anchieta, M. S. Pita, and D. Micheline, "Reconstruction of Skull Defects : Currently Available Materials," vol. 20, no. 5, pp. 1512-1518, 2009, doi: 10.1097/SCS.0b013e3181b09b9a

[13] E. S. Thian et al., "Zinc-substituted hydroxyapatite: a biomaterial with enhanced bioactivity and antibacterial properties," pp. 437-445, 2013, doi: 10.1007/s10856-012-4817-x.

[14] P. Sharma and P. M. Pandey, "Corrosion behaviour of the porous iron scaffold in simulated body fluid for biodegradable implant application," Mater. Sci. Eng. C, vol. 99, pp. 838-852, 2019, doi: 10.1016/j.msec.2019.01.114.

[15] Y. Chen, Z. Xu, C. Smith, and J. Sankar, "Recent advances on the development of magnesium alloys for biodegradable implants," Acta Biomater., vol. 10, no. 11, pp. 4561-4573, 2014, doi: 10.1016/j.actbio.2014.07.005.

[16] D. K. Pathak and P. M. Pandey, "An experimental investigation of the fabrication of biodegradable zinc-hydroxyapatite composite material using microwave sintering," Proc. Inst. Mech. Eng. Part C J. Mech. Eng. Sci., vol. 234, no. 14, pp. 2863-2880, 2020, doi: 10.1177/0954406220910445.

[17] D. Lytkina et al., "Synthesis and Properties of Zinc-Modified Hydroxyapatite," pp. 1-12, 2020.

[18] J. pu ZHENG, L. jian CHEN, D. yuan CHEN, C. sheng SHAO, M. fei YI, and B. ZHANG, "Effects of pore size and porosity of surfacemodified porous titanium implants on bone tissue ingrowth," Trans. Nonferrous Met. Soc. China (English Ed., vol. 29, no. 12, pp. 2534 2545, 2019, doi: 10.1016/S1003-6326(19)65161-7.
[19] A. Diez-Escudero, B. Andersson, C. Persson, and N. P. Hailer, "Hexagonal pore geometry and the presence of hydroxyapatite enhance deposition of mineralized bone matrix on additively manufactured polylactic acid scaffolds," Mater. Sci. Eng. C, vol. 125, no. December 2020, p. 112091, 2021, doi: 10.1016/j.msec.2021.112091.

[20] V. Karageorgiou and D. Kaplan, "Porosity of 3D biomaterial scaffolds and osteogenesis," Biomaterials, vol. 26, no. 27, pp. 5474 5491, 2005, doi: 10.1016/j.biomaterials.2005.02.002.

[21] M. A. Lopez-Heredia et al., "Bone growth in rapid prototyped porous titanium implants," J. Biomed. Mater. Res. - Part A, vol. 85, no. 3, pp. 664-673, 2008, doi: 10.1002/jbm.a.31468.

[22] Z. Chen et al., "Influence of the pore size and porosity of selective laser melted Ti6A14V ELI porous scaffold on cell proliferation, osteogenesis and bone ingrowth," Mater. Sci. Eng. C, vol. 106, no. October 2019, p. 110289, 2020, doi: 10.1016/j.msec.2019.110289.

[23] W. N. F. S. W. Dagang, J. Mahmud, N. F. A. Manan, and A. H. Abdullah, "The reconstruction of three-dimensional (3D) model of the right parietal-temporal implant," AIP Conf. Proc., vol. 2344, no. May, 2021, doi: 10.1063/5.0047476.

[24] P. Haen, G. Dubois, P. Goudot, and T. Schouman, "Comparative finite element analysis of skull mechanical properties following parietal bone graft harvesting in adults," J. Cranio-Maxillofacial Surg., vol. 46, no. 2, pp. 329-337, 2018, doi: 10.1016/j.jcms.2017.11.020.

[25] [25] C. Holberg and I. Rudzki-Janson, "Stresses at the cranial base induced by rapid maxillary expansion," Angle Orthod., vol. 76, no. $4, \quad$ pp. 543-550, 2006, doi: 10.1043/00033219(2006)076[0543:SATCBI]2.0.CO;2.

[26] [26] J. Pinc et al., "Characterization of newly developed zinc composite with the content of 8 wt. \% of hydroxyapatite particles processed by extrusion," Materials (Basel)., vol. 13, no. 7, 2020, doi: 10.3390/ma13071716. 